\title{
Destruction of Peroxide Explosives
}

J.C. Oxley, ${ }^{1}$ J.L. Smith, ${ }^{1}$ J. Huang, ${ }^{1}$ Wei Luo ${ }^{1}$

${ }^{1}$ Chemistry Department, University of Rhode Island, Kingston, RI 02881 
ABSTRACT: Chemicals containing multiple peroxide functionalities, such as triacetone triperoxide (TATP), diacetone diperoxide (DADP), or hexamethylene triperoxide diamine (HMTD), can be explosive. They are impractical and are not used by legitimate military groups because they are shock and heat sensitive compared to military explosives. They are attractive to terrorists because synthesis is straightforward, requiring only a few easily obtained ingredients. This paper discusses methods to degrade peroxide explosives chemically, at room temperature. Of particular interest is finding an allliquid chemical solution that can be sprayed over solid peroxide "finds" or in which peroxide saturated materials could be immersed and the peroxide would be destroyed with no further handling. The desired chemical solution should destroy within hours either TATP or HMTD so that white illicit explosive would not require prior characterization. While a number of mixtures were found effective, strong acids proved the most useful against the solid peroxide materials; however, on a 8 g scale addition of less than $1 \mathrm{~mL}$ concentrated sulfuric acid caused TATP to detonate. Thus, this technique should only be used to destroy very small quantities.

KEYWORDS: forensic science, peroxides, destruction, TATP, DADP, HMTD, hydrogen peroxide, explosives 
Improvised Explosive Devices (IEDs) may use conventional military explosives configured or re-configured for a particular application, or they can be homemade devices powered by explosives which are relatively easy to make. Device construction is based on material availability and the creator's knowledge and imagination. In the U.S., most bombings use small, smokeless or black powder devices because the bombs are being used as murder weapons and because these powders are not heavily regulated. In Iraq, bombs are larger because they are the weapons of guerilla warfare and military explosives in the form of mortars, artillery shells, and landmines are ubiquitous. In the past, one of the major difficulties in bomb design was acquisition of initiating explosives. These are essential to the bomb function but not readily made. Typically, they required theft or illegal purchase. The ready knowledge of how to prepare peroxide explosives has been a major boon to the would-be bomber. While explosive performance of peroxide explosives is poorer than TNT, the Internet provides recipes and bulletin boards of advice on how to prepare initiating explosives such as DADP, TATP, and HMTD, from readily acquired ingredients (Fig. 1). For law enforcement this has magnified the problems of detection and destruction.

Currently, the safest way to dispose of illegal explosives is to blow-in-place. This procedure keeps law enforcement from handling and transporting these highly sensitive materials. However, because relatively small quantities of peroxide explosives are usually discovered and they are frequently found in apartments and other high-population density areas, blow-in-place protocols are impractical. One of the goals of this work is to find a safe, effective, field-usable destruction method. A few publications have addressed this issue; two have suggested copper and tin salts to effect destruction at elevated temperature; ${ }^{1,2}$ one used mineral acids and elevated temperature. ${ }^{3}$ These articles were used as the starting point in a search for a room-temperature, chemical destruction method for peroxides. 


\section{Experimental Section}

\section{Destruction of Peroxide Explosives}

DADP, TATP and HMTD were prepared in our laboratory., ${ }^{4,5}$ For initial destruction testing, a stock solution of TATP was made by dissolving it in tetrahydrofuran (THF) or ethanol (EtOH) to create a $200 \mathrm{mg} / \mathrm{mL}$ solution; typically, $5 \mathrm{~mL}$ of this solution was used. DADP and HMTD solutions were made in the same manner. The destruction reagents, such as a metal and metal chloride or sulfate salts were added to an Agilent $20 \mathrm{~mL}$ flat-bottom vial. Distilled water $(5 \mathrm{~mL})$ was added and stirred until the salts dissolved. In some cases, sulfuric acid was added to adjust the $\mathrm{pH}$ of the aqueous solution. Five milliliters of the TATP, DADP or HMTD stock solution in THF or ethanol was added to the vial, and the mixture was stirred for 24 hours and then analyze for remaining peroxide. If particulate was still visible, the slurry was allowed to settle. A $100 \mu \mathrm{L}$ syringe was used to transfer $0.100 \mathrm{~mL}$ reaction slurry/solution into a $2 \mathrm{~mL}$ volumetric flask, and the flask was filled with acetonitrile. $\mathrm{Na}_{2} \mathrm{SO}_{4}$ (anhydrous) was added to the volumetric flask to removed traces of water. If the solution had been acidified, a bit of $\mathrm{NaHCO}_{3}$ (anhydrous) was added to neutralize the solution. It should be noted that combinations listed as "ambient" were subject to no $\mathrm{pH}$ adjustment. Solutions were filtered (Millex-FG syringe filters) into $2 \mathrm{~mL}$, amber screw-cap GC vials, which were sealed with PTFE-septa screw-caps to await $\mathrm{GC} / \mu \mathrm{ECD}$ analysis.

To determine whether solution destruction techniques would work on solid samples, 5 or $25 \mathrm{mg}$ samples of DADP, TATP or HMTD were placed in test tubes and treated with various reagents, typically 20 drops. Peroxide to reagent mole ratio was generally 1 to 5 . The mixtures sat at room temperature without stirring for up to 12 hours. After the soak time, $5 \mathrm{~mL}$ pentane or acetonitrile was added to the test tube to dissolve the remaining peroxide, and a $100 \mathrm{uL}$ aliquot of that solution was transferred into a $1 \mathrm{~mL}$ volumetric flask which was then filled to the mark with either pentane or 
acetonitrile. If acetonitrile was used, $\mathrm{MgSO}_{4}$ (anhydrous) was added to the volumetric flask to removed traces of water, and, when necessary, a small amount of anhydrous $\mathrm{NaHCO}_{3}$ was added to neutralize the solution. GC/uECD was used to quantify the peroxide compound.

\section{Gas Chromatography (GC) Analyses}

GC-uECD was used to determine the amount of peroxide compound in the solution. An Agilent $6890 \mathrm{GC}$ with u-ECD and a J\&W DB-5 column [30m x $0.25 \mathrm{~mm} \times 0.25 \mathrm{um}$ (film)] was employed. The inlet was set at $170^{\circ} \mathrm{C}$ with a 5:1 split ratio. The oven temperature started at $60^{\circ} \mathrm{C}$; after a 1 minute hold at $60^{\circ} \mathrm{C}$, it was increased to $250^{\circ} \mathrm{C}$ at a ramp of $20^{\circ} /$ minute. The flow rate of helium in the column was constant at $4.0 \mathrm{~mL} / \mathrm{minute}$. The u-ECD detector was held at $300^{\circ} \mathrm{C}$. Under these conditions, TATP retention time was 4.0 minutes; and DADP retention, 2.1 minutes. For HMTD all the GC conditions were the same as above except that the inlet was set at $250^{\circ} \mathrm{C}$ with a 5:1 split ratio. The oven temperature started at $70^{\circ} \mathrm{C}$; it was increased to $250^{\circ} \mathrm{C}$ at a ramp of $20^{\circ}$ /minute. The flow rate of helium in the column was constant at $8.0 \mathrm{~mL} /$ minute. Under these conditions, HMTD retention time was 5.2 minutes. In all cases, untreated peroxide sample controls were analyzed along side those treated for chemical destruction. This allowed direct determination of percent destruction from the ratios of the untreated to treated peak areas. Typical chromatograms for untreated TATP, DADP and HMTD are shown in Figures 2, 3 and 4, respectively.

\section{Results and Discussion}

\section{Destruction of THF Solutions of TATP}

Previous work reported that TATP could be destroyed by reaction with tin (II) chloride or copper compounds at elevated temperatures. ${ }^{1-3}$ In this study a number of metal salts were used to attempt the destruction of TATP. When it was observed that they did not function alone, metal or acid was added to enhance reactivity. The protocol involved dissolving TATP in THF or other solvent and adding an aqueous solution of the metal salt, with or without metal or acid. After a period of stirring at room 
temperature, usually 24 hours, $100 \mathrm{uL}$ of the peroxide-containing solution was diluted in acetonitrile and analyzed by GC/uECD to determine the amount of peroxide compound remaining. Table 1 shows the percentage of TATP remaining after 24 hours exposure to various metal/metal salts; $0 \%$ indicates complete destruction of TATP, while $100 \%$ indicates essentially no destruction. Zinc and copper salts appear effective, but only when combined with metal. Neither was effective alone. The metal was required only in catalytic amounts. In contrast, more than an equivalent of the metal salt was required. In general, 3 equivalents were as effective as 5 (Table 2).

As would be expected peroxide destruction was most effective if all the species were in solution. In most studies THF was used to pre-dissolved TATP and the metal salt. However, methanol or ethanol was also effective in dissolving the metal salts. Under these circumstances after 24 hours all the TATP had disappeared. However, in chloroform and hexane, in which the metal salts were not soluble, no loss of TATP was observed. These results illustrate the importance of dissolving both the metal salt and the TATP. Slight differences in the performance of the chloride and sulfate salts are attributed to solubility differences. For example, $\mathrm{CuSO}_{4}$ was ineffective in destroying TATP if the THF solution of TATP was added to the water before the copper salt was fully dissolved.

It was found that combinations $\mathrm{ZnSO}_{4}$ and $\mathrm{CuCl}_{2}$ with $\mathrm{Zn}$ and $\mathrm{Cu}$ destroyed TATP within 24 hours at room temperature. To determine whether a full 24 hours was required several zinc and copper combinations at a 5:5: 1 ratio were tested. The results, shown in Figure 5, show the destruction could be complete in as little as 3 hours.

Tin salts have been reported effective in rapidly destroying TATP, but only at elevated temperatures. ${ }^{1,2}$ An attempt was made to promote room temperature reactivity with tin salts by adding metal and metal salts. While zinc or copper did not aid the action of the tin salts, zinc sulfate and copper chloride did (Table 3). Similarly, zinc sulfate or copper chloride added to KI and NaBr were found to be 
effective if acid were added to the solution (Table 4). Table 4 examines the effect on TATP solution of a number of oxidizing and reducing agents.

The combinations successful in destroying TATP were tested against DADP and HMTD. Since HMTD was not soluble in ethanol (EtOH), studies of that peroxide were conducted in THF only. At the ratio of 5:5:1 equivalents of metals to equivalents metal salt to equivalent peroxide, complete destruction of TATP, DADP, and HMTD was accomplished in 24 hours with most of the acidified combinations reported in Table 5.

Having found a number of combinations that destroy TATP when that species was dissolved in THF, we looked for a solvent more readily available to law enforcement. The first data column in Table 5 shows the loss of TATP after 24 hours when aqueous ethanol solutions of it and the reagents were used. In cases where the reaction had been incomplete in THF, it went further to completion in ethanol, presumably due to the greater miscibility of the reactants. Unfortunately, HMTD is not soluble in ethanol; therefore, in determining reactivity of DADP and HMTD with the same reagents, the peroxides were dissolved in THF. Table 5 shows there are a number of soluble and insoluble chemical combinations that destroy all three peroxides.

\section{Destruction of Solid Peroxides}

Generally, HMTD was destroyed more readily than TATP; and DADP was the most difficult to decompose (Table 5). This is in line with their thermal stabilities. In some cases, GC-ECD analysis showed that TATP had been consumed, but DADP was present; it may be formed during TATP decomposition. ${ }^{6}$ The ordering roughly follows their thermal stabilities. Since HMTD was the most easily destroyed in solution, it was the first candidate for solid peroxide destruction studies. In a vial, one of the following salts ( $\mathrm{NaBr}, \mathrm{KMNO}_{4}, \mathrm{CuCl}_{2}, \mathrm{ZnCl}_{2}, \mathrm{ZnSO}_{4}, \mathrm{SnSO}_{4}$, sulfuric acid only) was placed on top of $5 \mathrm{mg}$ of HMTD; four drops of an aqueous sulfuric acid solution were added; and the mixture was allowed to stand overnight. The mole ratio of salt to HMTD was 5 to 1 ; the neat acid was diluted 1 to 1 
with water or 1 to 5 with water; nevertheless, in all cases consumption of HMTD was complete after 14 hours. Using the same protocol the destruction of TATP was attempted, and the reaction was monitored over a 12-hour interval. None of the acids which had been diluted 1 to 5 with water destroyed TATP completely within that time, nor did battery acid (labeled "battery" in Table 6). A number of combinations of chemicals resulted in complete TATP destruction within five to eight hours, but the goal was complete destruction in under 2 hours. Meeting that criteria, were only the concentrated mineral acids - methyl sulfonic acid (99\%), sulfuric acid (98\%), nitric acid (70\%) and hydrochloric acid (36\%) (Table 6). This is in line with the report ${ }^{3}$ that hydrobromic acid destroys HMTD and hydroiodic acid destroys TATP within 2 hours. Warning: The destruction of $10 \mathrm{~g}$ of TATP confined in a plastic vial was attempted remotely using less than $1 \mathrm{~mL}$ concentrated sulfuric acid. The sample detonated. This mode of destruction should be used for very small samples only.

\section{Conclusions}

The goal was to find a chemical "cocktail" that when sprayed on any of the sensitive solid peroxides, would cause quiescent decomposition without further handling. Destruction of TATP, DADP, and HMTD solutions could be affected in 24 hours at room temperature by the application of $\mathrm{ZnSO}_{4}$, or $\mathrm{CuCl}_{2}$ if these salts were used in combination with (a) zinc or copper metal; (b) tin chloride or sulfate salts; (c) $\mathrm{KMnO}_{4}, \mathrm{NH}_{2} \mathrm{NH}_{2}$, $\mathrm{KI}$, or NaBr. Reagents (a) or (b) are effective but yield slurries rather than solutions. Any of the reagents listed in (c) when combined with zinc sulfate or copper chloride are water soluble. Most of these systems affect destruction more rapidly when acidified; this may be due to increased solubility.

This study demonstrated that strong acids, methyl sulfonic acid (99\%), sulfuric acid (98\%), and nitric acid (70\%), when applied directly to solid (5 mg) TATP, DADP, and HMTD, even without stirring, accomplished destruction in 15 minutes. However, this destruction technique is unsuitable for use in even gram quantities of TATP. We believe the reaction with acid is exothermic. While this is not 
noticeable on the milligram-scale, it provides sufficient energy to initiate the TATP on the gram-scale. Gram-scale tests have not been performed on DADP nor HMTD. Thus, further safety tests are required. Nevertheless, it can readily be used by canine trainers to simply dispose of the small quantities of these peroxides found on canine training aids.

Acknowledgements

The authors wish to thank the Department of Homeland Security, Science and Technology Directorate for supporting this work. 


\section{Reference}

1. Bellamy, A.J.“Triacetone Triperoxide: Its Chemical Destruction” J. Forensic Sci 1999;44(3):603-8.

2. Costantini, M. “Destruction of Acetone Peroxides” U.S. Patent 5,003,109; Mar. 26, 1991.

3. Matyas, R. "Chemical Decomposition of Triacetone Triperoxide and Hexamethylene triperoxide diamide Nitrem Symposium, Pardubice, CZ, 2004;241-247.

4. Oxley, J.C.; Smith, J.L.; Chen, H. "Decomposition of Multi-Peroxidic Compound: Triacetone Triperoxides (TATP)” Prop Explos Pyrotech 2002;27:209-216.

5. Oxley, J.C.; Smith, J.L.; Chen, H.; Cioffi, E. "Decomposition of Multi-Peroxidic Compounds: Part

II: Hexamethylene Triperoxide Diamine (HMTD)" Thermochem Acta 2002;388(1-2):215-225.

6. Matyas, R.; Pachman, J.; Ang, H.-G. "Study of TATP: Spontaneous Transformation of TATP to

DADP“ Prop Explos Pyrotech 2008;33:89-91

Additional information and reprint requests:

Jimmie C. Oxley, $\mathrm{PhD}$

Chemistry Department

University of Rhode Island

Kingston RI 02881

Phone/fax:401-874-2103

E-mail: joxley@chm.uri.edu 


\section{LIST OF TABLES}

TABLE 1-Metal/ Metal Salts Effectiveness in Destroying TATP in THF Solution (10mg/15mL)

TABLE 2-Metal/Metal Salt Ratio Effect on TATP Destruction in THF (10 mg/15 mL)

TABLE 3-Effects of $\mathrm{SnCl}_{2}$ and $\mathrm{SnSO}_{4}$ on the destruction of TATP

TABLE 4-The effect of other salts on the destruction of TATP

TABLE 5-Best Candidates for Destruction of TATP, DADP and HMTD Solutions (1 peroxide: 5 reactant $1: 5$ reactant 2 )

TABLE 6-Time Required to Destroy Solid TATP, DADP or HMTD with Various Reagents 


\section{LIST OF FIGURES}

FIGURE 1-Structures of DADP, TATP and HMTD

FIGURE 2- Typical chromatogram of untreated TATP in acetonitrile by $6890-\mu \mathrm{ECD}$ $\begin{array}{lll}\text { 1) acetonitrile } & \text { 2) TATP }\end{array}$

FIGURE 3-Typical chromatogram of untreated DADP in acetonitrile by $6890-\mu \mathrm{ECD}$ 1) acetonitrile 2) DADP

FIGURE 4-Typical chromatogram of untreated HMTD in acetonitrile by $6890-\mu \mathrm{ECD}$ 1) decomposition product of HMTD 2) HMTD

FIGURE 5- Destruction of TATP over 24 hours using various M/MX aqueous mixtures 


\begin{tabular}{|c|c|c|c|c|c|c|}
\hline metal salt & metal & $\begin{array}{l}\text { equivalents } \\
\text { salt:TATP }\end{array}$ & $\begin{array}{l}\text { equivalents } \\
\text { metal:TATP }\end{array}$ & added acid & solvent & $\begin{array}{l}\text { TATP remaining } \\
\text { after } 24 \mathrm{hr} \text { r.t. }\end{array}$ \\
\hline $\mathrm{FeSO} 4$ & & 1 to 9 salt to 1 TATP & & none or $\mathrm{HCl}$ & THF & $100 \%$ \\
\hline $\mathrm{FeCl}_{2}$ & & 1 to 3 salt to 1 TATP & & none or $\mathrm{HCl}$ & THF & $100 \% *$ \\
\hline CuSO4 & & 2 & & none or $\mathrm{HCl}$ & THF & $100 \%$ \\
\hline $\mathrm{CuCl} 2$ & & 2 to 3 salt to 1 TATP & & none or $\mathrm{HCl}$ & THF & $100 \%$ \\
\hline $\mathrm{ZnSO}$ & & 1 & & $\mathrm{H} 2 \mathrm{SO} 4$ & THF & $32 \%$ \\
\hline $\mathrm{ZnCl} 2$ & & 3 & & $\mathrm{H} 2 \mathrm{SO} 4$ & THF & $60 \%$ \\
\hline $\mathrm{CoCl} 2$ & & 1 & & & $\mathrm{THF}$ & $100 \%$ \\
\hline $10 \% \operatorname{Pd}(\mathrm{C})$ & & 1 & & & THF & $100 \%$ \\
\hline $\mathrm{MgCl}_{2}$ & & 1 & & & THF & $100 \%$ \\
\hline $\mathrm{FeCl}_{3}$ & & & & $\mathrm{pH}=1$ & $\mathrm{EtOH}$ & $34 \%$ \\
\hline $\mathrm{Co}\left(\mathrm{NO}_{3}\right)_{2}$ & & & & 1 & $\mathrm{EtOH}$ & $8 \%$ \\
\hline $\mathrm{CrCl}_{3} 6 \mathrm{H}_{2} \mathrm{O}$ & & & & 1.3 & $\mathrm{EtOH}$ & $15 \%$ \\
\hline $\mathrm{CrCl}_{3} 6 \mathrm{H}_{2} \mathrm{O}$ & & & & 1 & $\mathrm{EtOH}$ & $0 \%$ \\
\hline $\mathrm{Cr}_{2} \mathrm{O}_{3}$ & & & & 1.5 & EtOH insoluble & $0 \%$ \\
\hline $\mathrm{Cr}_{2} \mathrm{O}_{3}$ & & & & 1 & $\mathrm{EtOH}$ insoluble & $0 \%$ \\
\hline FeSO4 & $\mathrm{Fe}$ & 3 & 3 & & THF & $100 \%$ \\
\hline $\mathrm{FeCl} 2$ & $\mathrm{Fe}$ & 3 & 3 & & THF & $100 \%$ \\
\hline $\mathrm{ZnSO4}$ & $\mathrm{Zn}$ & 3 & 3 & & $\mathrm{THF}$ & $0 \%$ \\
\hline $\mathrm{ZnCl} 2$ & $\mathrm{Zn}$ & 3 & 3 & & THF & $25 \%$ \\
\hline CuCl2 & $\mathrm{Cu}$ & 3 & 3 & & $\mathrm{THF}$ & $5 \%$ \\
\hline CuSO4 & $\mathrm{Cu}$ & 3 & 3 & & THF & $35 \%$ \\
\hline None & $\mathrm{Cu}$ & 0 & 6 & & $\mathrm{THF}$ & $100 \%$ \\
\hline None & $\mathrm{Zn}$ & 0 & 6 & & THF & $100 \%$ \\
\hline $\mathrm{ZnSO4}$ & $\mathrm{Cu}$ & 3 & 3 & & $\mathrm{THF}$ & $0 \%$ \\
\hline Cuso4 & Zn & 3 & 3 & & THF & $100 \%$ \\
\hline $\mathrm{MSO}_{4}$ & $\mathrm{M}=\mathrm{Mg}, \mathrm{Al}, \mathrm{Fe}$ & 3 & 3 & & THF & $100 \%$ \\
\hline $\mathrm{M}(\mathrm{Cl})_{\mathrm{n}}$ & $M=M g, A l, F e$ & 3 & 3 & & THF & $100 \%$ \\
\hline
\end{tabular}

* $44 \%$ remains if $r x$ in ethanol

Table 1 


\begin{tabular}{|ccccc|}
\hline metal salt & metal & $\begin{array}{c}\text { equivalents } \\
\text { salt:TATP }\end{array}$ & $\begin{array}{c}\text { equivalents } \\
\text { metal:TATP }\end{array}$ & $\begin{array}{c}\text { TATP remaining } \\
\text { after 24 hr r.t. }\end{array}$ \\
\hline $\mathrm{ZnSO}$ & $\mathrm{Zn}$ & 0.3 & 3 & $\mathbf{7 7 \%}$ \\
$\mathrm{ZnSO} 4$ & $\mathrm{Zn}$ & 3 & 0.3 & $\mathbf{0 \%}$ \\
$\mathrm{ZnSO} 4$ & $\mathrm{Zn}$ & 3 & 0 & $100 \%$ \\
$\mathrm{ZnSO} 4$ & $\mathrm{Zn}$ & 0 & 6 & $100 \%$ \\
\hline $\mathrm{CuCl} 2$ & $\mathrm{Cu}$ & 0.3 & 3 & $\mathbf{4 4 \%}$ \\
$\mathrm{CuCl} 2$ & $\mathrm{Cu}$ & 3 & 0.3 & $\mathbf{5 \%}$ \\
$\mathrm{CuCl} 2$ & $\mathrm{Cu}$ & 3 & 0 & $100 \%$ \\
$\mathrm{CuCl} 2$ & $\mathrm{Cu}$ & 0 & 6 & $100 \%$ \\
\hline $\mathrm{ZnSO4}$ & $\mathrm{Zn}$ & 3 & 3 & $\mathbf{0} \%$ \\
$\mathrm{CuCl} 2$ & $\mathrm{Cu}$ & 3 & 3 & $\mathbf{5 \%}$ \\
$\mathrm{ZnSO} 4$ & $\mathrm{Cu}$ & 3 & 3 & $\mathbf{0 \%}$ \\
\hline
\end{tabular}

Table 2 


\begin{tabular}{|cccccc|}
\hline Metal Salts(I) & Metal & Metal Salts (II) & pH & Solvent & $\begin{array}{c}\text { TATP remaing } \\
\text { after 24 hr r.t. }\end{array}$ \\
\hline SnCl2 & Zn or Cu & & 1 or ambient & EtOH or THF & $100 \%$ \\
SnSO-4 & Zn or Cu & & 1 or ambient & EtOH or THF & $100 \%$ \\
\hline SnCl2 & & $\mathrm{ZnSO} 4$ & ambient & EtOH or THF & $<10 \%$ \\
SnSO4 & & $\mathrm{CuCl} 2$ & ambient & EtOH or THF & $<1 \%$ \\
\hline
\end{tabular}

Table 3 


\begin{tabular}{|c|c|c|c|c|}
\hline Metal Salts(I) & Metal Salts (II) & $\mathrm{pH}$ & Solvent & $\begin{array}{l}\text { TATP remaing } \\
\text { after } 24 \mathrm{hr} \text { r.t. }\end{array}$ \\
\hline $\mathrm{KI}$ & & $1 / 0.6$ & $\overline{\mathrm{EtOH}}$ & $60 \% / 0 \%$ \\
\hline $\mathrm{KI}$ & $\mathrm{CuCl}_{2}$ or $\mathrm{ZnSO}_{4}$ & 1 & $\mathrm{EtOH}$ & $<5 \%$ \\
\hline $\mathrm{NaBr}$ & $\mathrm{CuCl}_{2}$ or $\mathrm{ZnSO}_{4}$ & 1 & $\mathrm{EtOH}$ & $<8 \%$ \\
\hline $\mathrm{KI}$ & $\mathrm{CuCl}_{2}$ or $\mathrm{ZnSO}_{4}$ & ambient & $\mathrm{EtOH}$ & $<80 \%$ \\
\hline $\mathrm{NaBr}$ & $\mathrm{CuCl}_{2}$ or $\mathrm{ZnSO}_{4}$ & ambient & $\mathrm{EtOH}$ & $100 \%$ \\
\hline $\mathrm{KSCN}$ & $\mathrm{CuCl}_{2}$ or $\mathrm{ZnSO}_{4}$ & 1 or ambient & EtOH or THF & $100 \%$ \\
\hline $\mathrm{Na}_{2} \mathrm{SO}_{3}$ & & 1/ambient & EtOH or THF & $60 \% / 100 \%$ \\
\hline $\mathrm{Na}_{2} \mathrm{~S}_{2} \mathrm{O}_{3}$ & $\mathrm{CuCl}_{2}$ or $\mathrm{ZnSO}_{4}$ & 1 or ambient & EtOH or THF & $100 \%$ \\
\hline $\mathrm{KMnO}_{4}$ & & 1 & $\mathrm{EtOH}$ & $50 \%$ \\
\hline $\mathrm{KMnO}_{4}$ & $\mathrm{MnSO}_{4}$ & 1 & $\mathrm{EtOH}$ & $29 \%$ \\
\hline $\mathrm{KMnO} 4$ & $\mathrm{ZnSO}_{4}$ & 1 & $\mathrm{EtOH}$ & $8 \%$ \\
\hline $\mathrm{KMnO} 4$ & $\mathrm{CuCl}_{2}$ & 1 & $\mathrm{EtOH}$ & $60 \%$ \\
\hline $\mathrm{KMnO} 4$ & $\mathrm{Zn}$ & 1 & EtOH insoluble & $39 \%$ \\
\hline $\mathrm{NH}_{2} \mathrm{NH}_{2}$ & & ambient & $\mathrm{EtOH}$ & $100 \%$ \\
\hline $\mathrm{NH}_{2} \mathrm{NH}_{2}$ & $\mathrm{ZnSO}_{4}$ & ambient & $\mathrm{EtOH}$ & $100 \%$ \\
\hline $\mathrm{NH}_{2} \mathrm{NH}_{2}$ & $\mathrm{CuCl}_{2}$ & ambient & $\mathrm{EtOH}$ & $48 \%$ \\
\hline $\mathrm{NH}_{2} \mathrm{NH}_{2}$ & $\mathrm{ZnSO}_{4}$ & 1 & $\mathrm{EtOH}$ & $100 \%$ \\
\hline $\mathrm{NH}_{2} \mathrm{NH}_{2}$ & $\mathrm{CuCl}_{2}$ & 1 & $\mathrm{EtOH}$ & $100 \%$ \\
\hline $\mathrm{NH}_{2} \mathrm{NH}_{2}$ & $\mathrm{CuCl}_{2}$ & 10 & $\mathrm{EtOH}$ & $46 \%$ \\
\hline $\mathrm{NH}_{2} \mathrm{NH}_{2}$ & $\mathrm{KI}$ & 10 & $\mathrm{EtOH}$ & $42 \%$ \\
\hline $\mathrm{NH}_{2} \mathrm{NH}_{2}$ & $\mathrm{Fe}$ & 10 & EtOH insoluble & $39 \%$ \\
\hline $\mathrm{NH}_{2} \mathrm{NH}_{2}$ & $\mathrm{Cu}$ & 10 & EtOH insoluble & $35 \%$ \\
\hline $\mathrm{P}(\mathrm{OEt})_{3}$ & & ambient & $\mathrm{EtOH}$ & $100 \%$ \\
\hline $\mathrm{PPh}_{3}$ & alone or $\mathrm{ZSO}_{4}$ & ambient & $\mathrm{EtOH}$ & $100 \%$ \\
\hline $\mathrm{SMe}_{2}$ & alone or $\mathrm{ZSO}_{4}$ & ambient & $\mathrm{EtOH}$ & $100 \%$ \\
\hline
\end{tabular}

Table 4 


\begin{tabular}{|c|c|c|c|c|c|c|}
\hline & & \multirow[t]{2}{*}{$\begin{array}{l}\text { solubility in } \\
\text { organic }\end{array}$} & \multirow[t]{2}{*}{$\mathrm{pH}$} & $\begin{array}{l}\text { TATP }(20 \mathrm{mg}) \\
\text { remaining }\end{array}$ & $\begin{array}{l}\text { DADP (10mg) } \\
\text { remaining }\end{array}$ & $\begin{array}{l}\text { HMTD (10mg) } \\
\text { remaining }\end{array}$ \\
\hline & & & & \multicolumn{3}{|c|}{5 eq reagent in $5 \mathrm{~mL}$ organic $+5 \mathrm{mLwater}$ after $24 \mathrm{~h}$} \\
\hline \multicolumn{2}{|c|}{ salt system } & & & THF Ethanol & THF & THF \\
\hline $\mathrm{Zn}$ & $\mathrm{ZnSO}_{4}$ & insoluble & ambient & $0 \%$ & $3 \%$ & $31 \%$ \\
\hline $\mathrm{Zn}$ & $\mathrm{ZnCl}_{2}$ & insoluble & ambient & $0 \%$ & $7 \%$ & $76 \%$ \\
\hline$\overline{\mathrm{Zn}}$ & $\mathrm{ZnSO}_{4}$ & insoluble & 1 & $0 \%$ & & $0 \%$ \\
\hline $\mathrm{Zn}$ & $\mathrm{ZnCl}{ }_{2}$ & insoluble & 1 & $0 \%$ & & $0 \%$ \\
\hline $\mathrm{Cu}$ & $\mathrm{CuCl}_{2}$ & insoluble & ambient & $5 \%$ & 0 & $1 \%$ \\
\hline $\mathrm{Cu}$ & $\mathrm{CuSO}_{4}$ & insoluble & ambient & $35 \%$ & $20 \%$ & $15 \%$ \\
\hline $\mathrm{SnCl}_{2}$ & $\mathrm{ZnSO}_{4}$ & insoluble & ambient & $1 \%$ & $7 \%$ & $1 \%$ \\
\hline $\mathrm{SnCl}_{2}$ & $\mathrm{CuCl}_{2}$ & insoluble & ambient & $0 \%$ & $5 \%$ & $0 \%$ \\
\hline $\mathrm{SnSO}_{4}$ & $\mathrm{ZnSO}_{4}$ & insoluble & ambient & $19 \%$ & $18 \%$ & $0 \%$ \\
\hline $\mathrm{SnSO}_{4}$ & $\mathrm{CuCl}_{2}$ & insoluble & ambient & $1 \%$ & $5 \%$ & $0 \%$ \\
\hline $\mathrm{KMnO}_{4}$ & $\mathrm{ZnSO}_{4}$ & soluble & ambient & $63 \%$ & $1 \%$ & $81 \%$ \\
\hline $\mathrm{KMnO}_{4}$ & $\mathrm{ZnSO}_{4}$ & soluble & 1 & $13 \%$ & $1 \%$ & $1 \%$ \\
\hline $\mathrm{KMnO}_{4}$ & & soluble & 1 & $0 \%$ & $23 \%$ & $1 \%$ \\
\hline $\mathrm{NH}_{2} \mathrm{NH}_{2}$ & $\mathrm{CuCl}_{2}$ & soluble & ambient & $4 \%$ & $0 \%$ & $0 \%$ \\
\hline $\mathrm{NH}_{2} \mathrm{NH}_{2}$ & $\mathrm{ZnSO}_{4}$ & soluble & ambient & $58 \%$ & -- & -- \\
\hline $\mathrm{KI}$ & none & soluble & 1 & $11 \%$ & $86 \%$ & $0 \%$ \\
\hline $\mathrm{KI}$ & $\mathrm{CuCl}_{2}$ & soluble & 1 & $5 \%$ & $41 \%$ & $0 \%$ \\
\hline $\mathrm{KI}$ & $\mathrm{ZnSO}_{4}$ & soluble & 1 & $3 \%$ & $51 \%$ & $0 \%$ \\
\hline $\mathrm{NaBr}$ & none & soluble & 1 & $8 \%$ & & $0 \%$ \\
\hline $\mathrm{NaBr}$ & $\mathrm{CuCl}_{2}$ & soluble & 1 & $2 \%$ & $67 \%$ & $0 \%$ \\
\hline $\mathrm{NaBr}$ & $\mathrm{ZnSO}_{4}$ & soluble & 1 & $3 \%$ & $37 \%$ & $0 \%$ \\
\hline
\end{tabular}

Table 5 


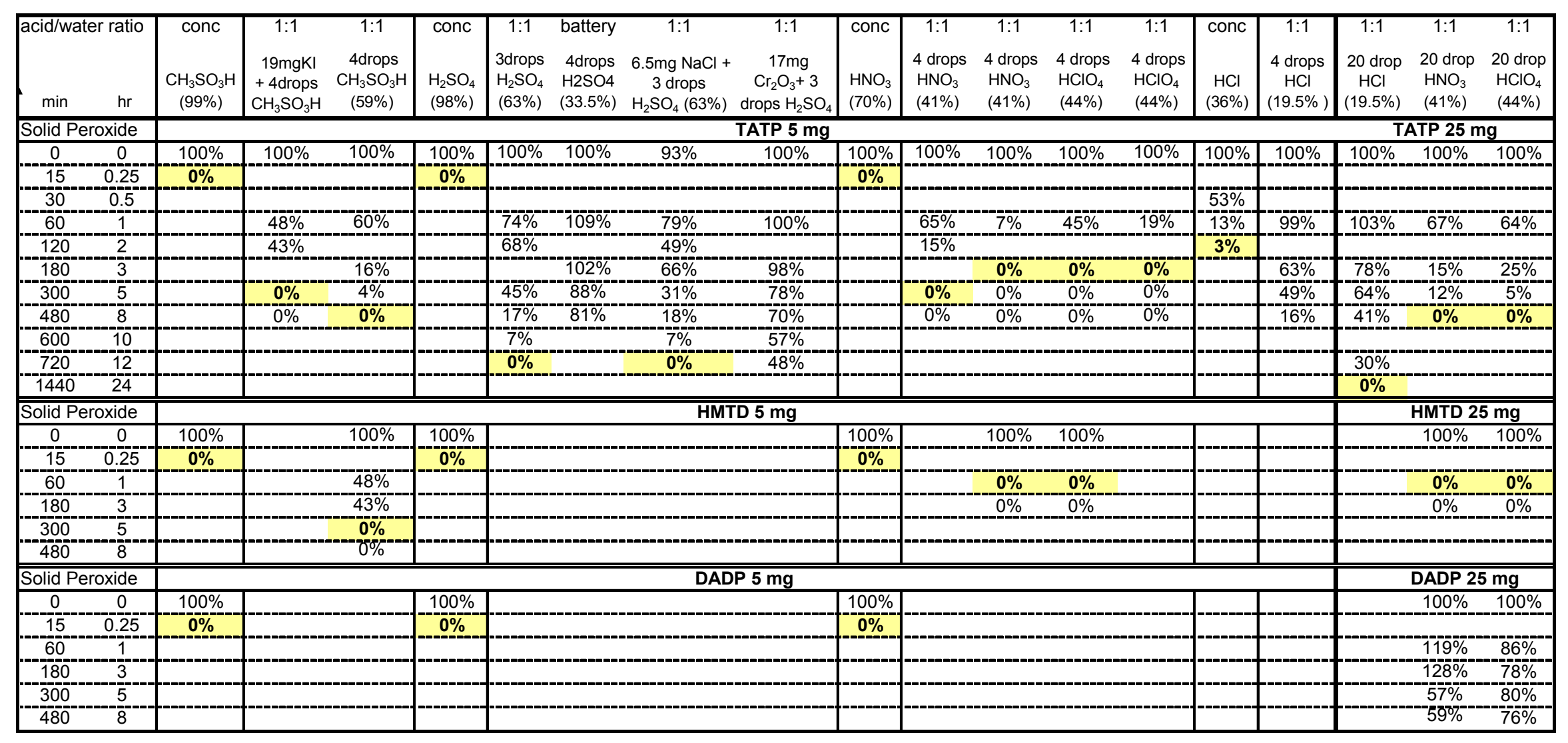

Table 6 


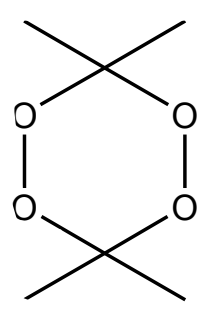

DA DP

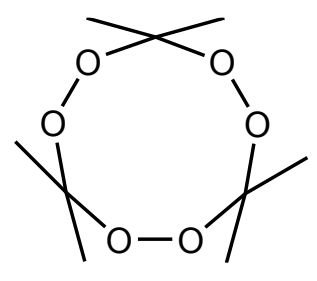

TATP

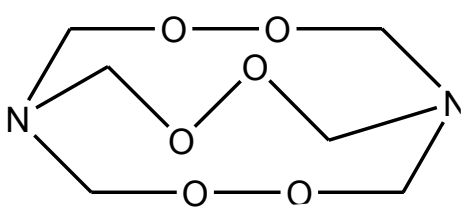

HMTD

Figure 1 


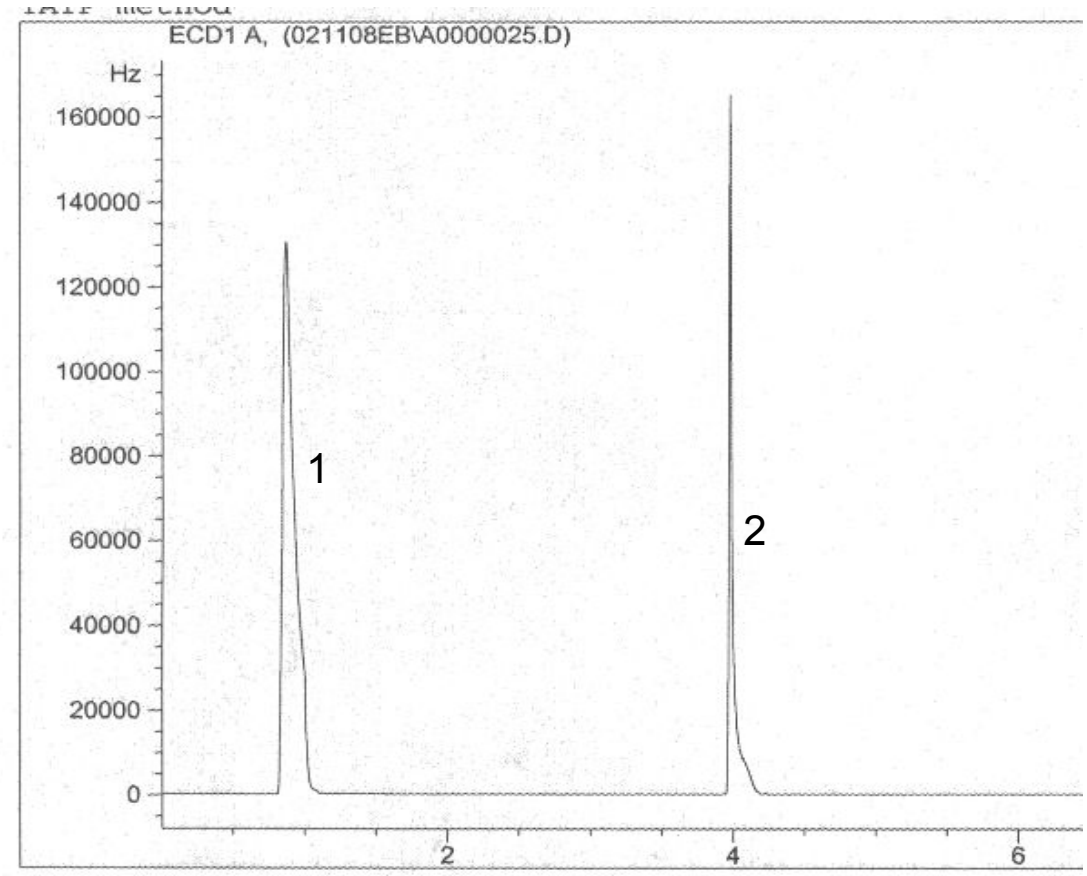

Figure 2 
TATP method

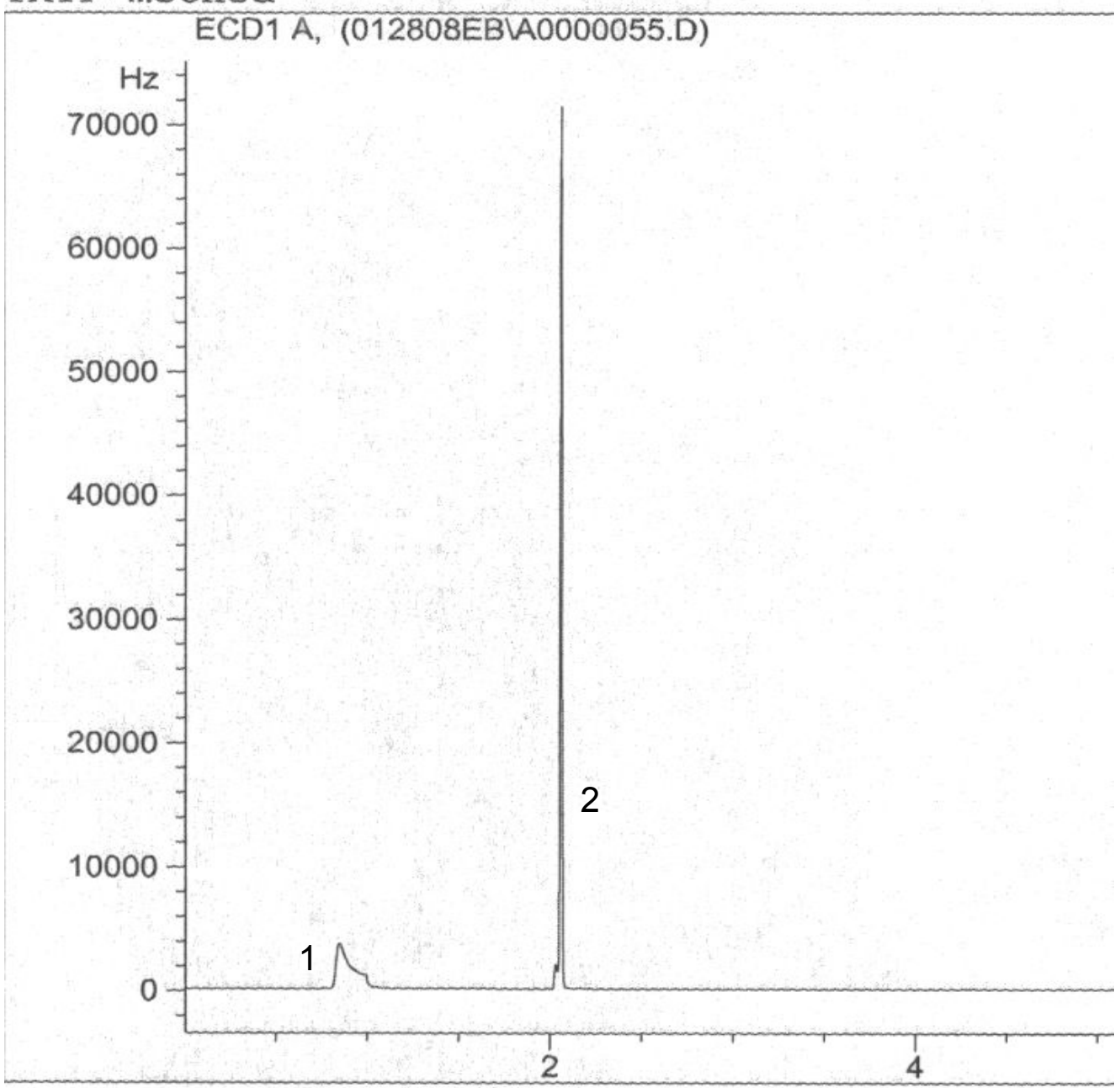

Figure 3 


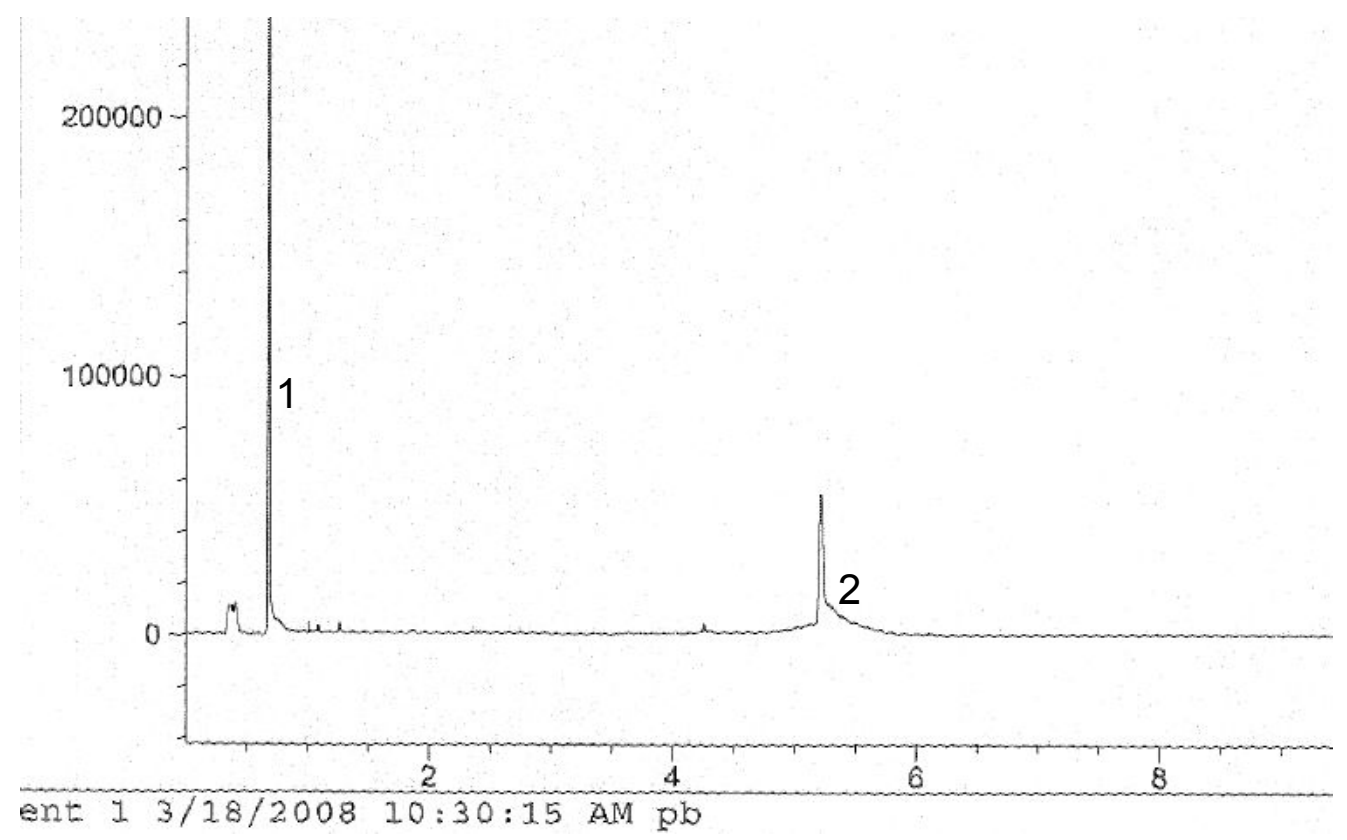

Figure 4 


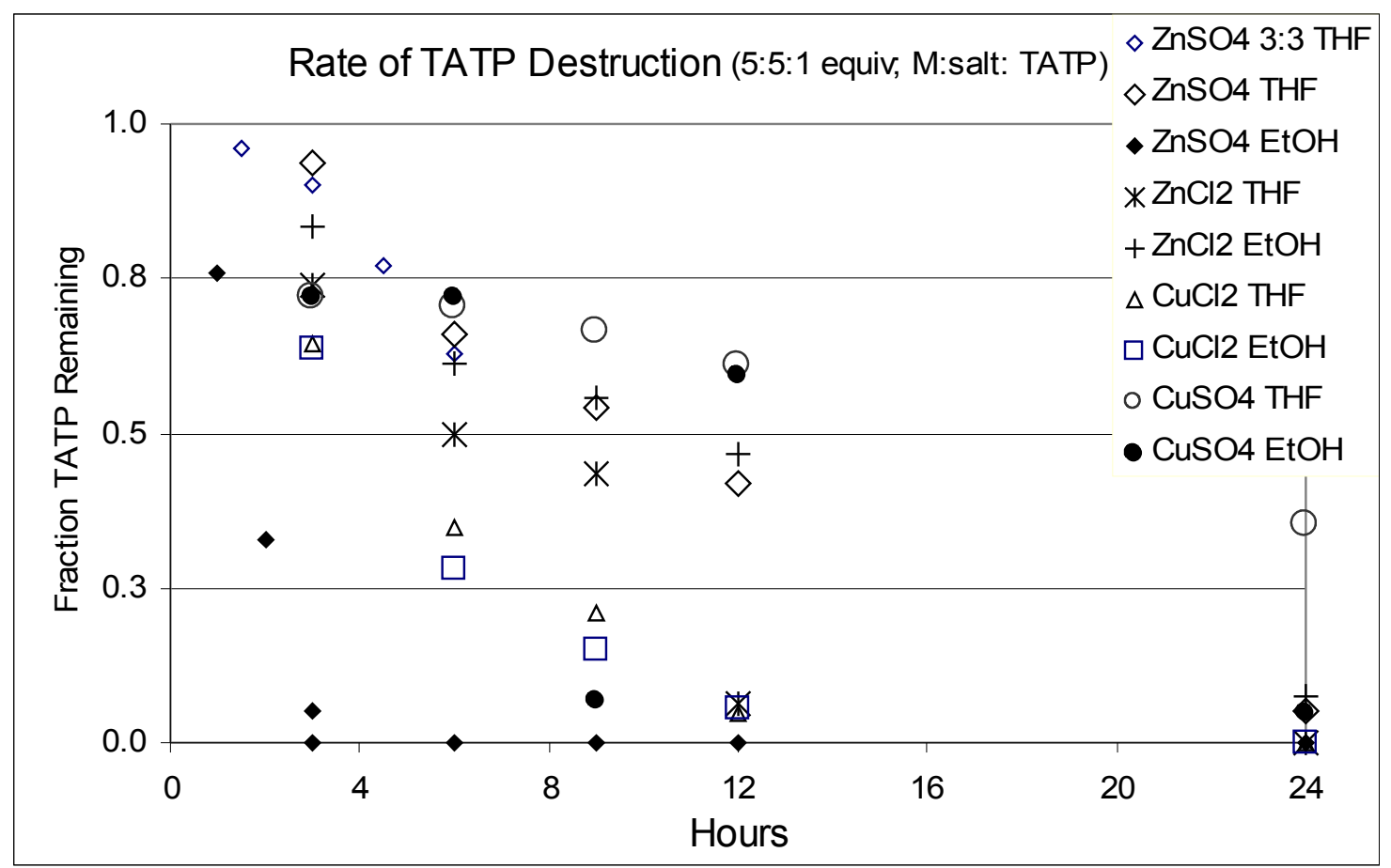

Figure 5 